This PDF is a selection from an out-of-print volume from the National Bureau of Economic Research

Volume Title: Aging Issues in the United States and Japan

Volume Author/Editor: Seiritsu Ogura, Toshiaki Tachibanaki and David A. Wise, editors

Volume Publisher: University of Chicago Press

Volume ISBN: 0-226-62081-6

Volume URL: http://www.nber.org/books/ogur01-1

Publication Date: January 2001

Chapter Title: Employeesâ€ $€^{\mathrm{TM}}$ Pension Benefits and the Labor Supply of Older Japanese Workers, 1980sâ€“"1990s

Chapter Author: Yukiko Abe

Chapter URL: http://www.nber.org/chapters/c10292

Chapter pages in book: (p. 273 - 306) 


\title{
Employees' Pension Benefits and the Labor Supply of Older Japanese Workers, 1980s-1990s
}

\author{
Yukiko Abe
}

\subsection{Introduction}

The population of Japan is aging rapidly. According to Ministry of Health and Welfare of Japan projections, the proportion of the population above the age of sixty-five years will reach about 25 percent by the year 2025. At the same time, the nation's social security benefits have increased substantially since the 1970 s, and retirees now receive a generous tax deduction for pension income. Because the Japanese public pension program is organized as a pay-as-you-go system, and because the large cohort of baby boomers will retire early in the twenty-first century, the current benefit and tax structure soon will place a substantial burden on younger workers. ${ }^{1}$

In an attempt to reduce this burden, the Japanese government has instituted several modifications to the pension system. For example, whereas full social security benefits used to start at age sixty for men covered by the Employees' Pension program, reductions in benefits to be phased in

Yukiko Abe is associate professor at Asia University.

The author wishes to thank the Ministry of Labor of Japan for permission to use the microdata sets of the Survey on Employment Conditions of Older Persons (1983, 1988, and 1992) and the Japan Foundation Center for Global Partnership for financial support. She also thanks David Cutler, Yasushi Ohkusa, Atsushi Seike, David Wise, and participants in the National Bureau of Economic Research-Japan Center for Economic Research Conference on the Economics of Aging for their comments. Any errors in this paper are the sole responsibility of the author, as are the opinions expressed in it.

1. There are three major public pension programs in Japan. The Employees Pension insurance system (EP) covers workers in the private sector. Public-sector employees and privateschool personnel are covered by mutual aid associations (MAAs) of several different types. The self-employed and farmers are covered by the National Pension (NP). Extensive discussions of the public pension system can be found in Ogura (1994) and Oguchi, Kimura, and Hatta (1996). 
between 2001 and 2013 mean that men aged sixty to sixty-four and covered by Employee Pension insurance (EP) will receive smaller pensions. ${ }^{2}$ Such reductions, as well as other changes in social security benefits and taxes, are likely to affect the number of older persons active in the labor market during the next few decades.

In the first section of this paper, therefore, I look at the recent employment history of Japanese men in this age group. Between the 1970s and the late 1980s their rate of participation in the labor market declined steadily; it rose in the early 1990s, then fell again between 1993 and 1996. Several economists (e.g., Seike and Shimada 1994) argue that the expansion of social security benefits in the 1970s is responsible for the decreasing employment rate for this group through the late 1980s. My initial focus on the subsequent rebound in paid employment of the early 1990s suggests several explanations for that rise. I then examine the effect on the labor supply of men aged sixty to sixty-four resulting from changes in the pension benefit scheme of the EP program. Throughout the paper I refer to workers sixty to sixty-four years old who have already applied for EP benefits and are therefore eligible to receive them as EP eligibles; people who are likely to qualify for EP benefits but have not yet applied for them are potential EP eligibles. ${ }^{3}$

In the past decade the Japanese government has cut pension benefits for working EP eligibles. In response to the criticism that such reductions distort labor supply of the elderly, the government several times has reformed the rules governing benefit reductions in an attempt to eliminate work disincentives. In the latter part of this paper, I examine the effect of these rule changes by comparing labor supply of older workers before and after the reform of the Employees' Pension Insurance Act (EPIA) instituted in 1989. The data I use come from the Survey on Employment Conditions of Older Persons (SECOP) for 1983, 1988, and 1992. Although EPIA reforms affect EP eligibles aged sixty to sixty-four, they do not apply to those aged sixty-five or older, nor to workers covered by non-EP public pension programs. I was therefore able to use the latter two groups as a control group for evaluating the response of EP eligibles to EPIA reform and its effect on the labor supply of men in this age group.

Even though regression estimates indicate that reductions in benefits that are related to earnings generally discourage labor supply of the

2. While nonworkers aged sixty to sixty-four stop making social security contributions, they will receive only the proportional part of the pension benefits (i.e., the amount proportional to their individual lifetime contributions). After age sixty-five, they will receive the base part (the standard pension amount received by all seniors) as well as the proportional part.

3. Application for determination of entitlement (saitei) by covered individuals (those who contributed to the EP before age sixty) is the necessary condition for receiving EP benefits. Based on this application, the benefit amount for the individual is calculated. Although the starting age for receiving EP benefits is sixty, many individuals covered by the program do not apply for EP benefits at that age. 
affected group, the 1989 EPIA reforms do not seem to have significantly encouraged employment among men aged sixty to sixty-four.

According to several other studies comparing the earnings distribution of EP eligibles and EP noneligibles (Tachibanaki and Shimono 1994; Seike and Shimada 1994), EP eligibles avoid benefit reductions by adjusting their earnings. ${ }^{4}$ However, while many of these studies suggest that reductions in benefits distort labor supply, none of the models used explicitly includes the institutional fact that benefit reductions apply only to EP eligibles who participate in EP at ages sixty to sixty-four. This fact has important implications for evaluations of the government's benefit reduction scheme, for the reasons outlined below.

There are several ways for working EP eligibles not to participate in EP, and thus to avoid benefit reductions. Employees' Pension benefits are cut only if the worker participates in EP through his or her current employer (i.e., pays the EP premium out of current earnings). In general, EP participation is required only when the following three conditions are all met: The worker is less than sixty-five years old, is employed in a private-sector establishment with more than five regular employees or in an incorporated enterprise of any number of employees, and works more hours than threequarters of the regular employees in the same establishment. A worker who does not meet these qualifications - for example, by working outside the private sector, part-time, or in self-employment - does not have to participate in EP. Based on my analysis shown below, about 30 percent of working EP-eligible males choose to work under conditions in which EP participation is not required. This sizable proportion of nonparticipating, working EP eligibles suggests then that benefit reductions are likely to affect labor supply by making self-employment, part-time work, or publicsector employment more attractive to those who might otherwise choose to work full-time in the private sector.

Because benefit reduction is most likely to affect the likelihood of and the hours of private-sector employment, I analyze overall labor force participation and private-sector employment separately in this paper. This procedure contrasts sharply with that of previous studies, which either examine work-hours decisions without regard to choice of work mode or fail to distinguish among various kinds of work, even though benefit reduction has different implications for different work modes.

This paper is organized as follows. In section 9.2, I present an overview of the trend in the labor supply of Japanese men aged sixty to sixty-four. In section 9.3, I explain the EP benefit rule for active workers and review its history from the 1980s to the present. In section 9.4, I explain the Sur-

4. Seike and Shimada (1994) employ a labor supply model that incorporates selection bias. Ogawa (1997) studies labor force participation by using a binary choice model. Amemiya and Shimono (1989) use a nested logit model to examine workers' choices among full-time work, part-time work, and no work. 


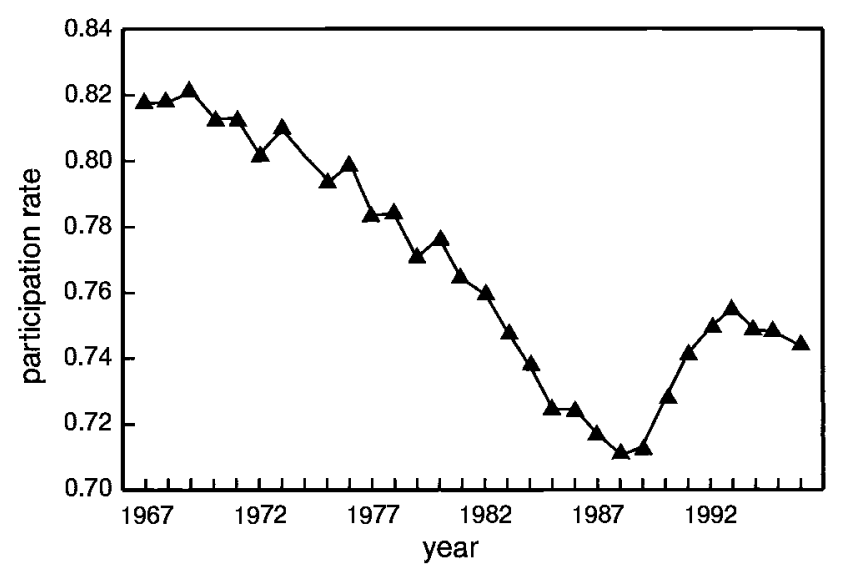

Fig. 9.1 Aggregate male labor force participation of men aged sixty to sixty-four Source: Labor Force Survey, Statistical Bureau, Management and Coordination Agency, various years.

vey on Employment Conditions of Older Persons (SECOP, Konenreisha Shūgyō Jittai Chōsa), which is the data set used in this paper. In section 9.5, I explain the descriptive statistics of work-mode choice and hours. In section 9.6, estimates from a reduced-form analysis are presented. The paper concludes with a discussion of the policy implications of the findings.

\subsection{Overview of the Labor Supply of Men Aged Sixty to Sixty-Four}

Between 1967 and the late 1980s, the labor force participation of sixtyto sixty-four-year-old Japanese men decreased; it then increased until 1993 before again declining somewhat between 1993 and 1996. This transition is shown in figure 9.1. The first decline is often attributed to the expansion of public pension benefits during the same period (e.g., Seike 1993). Possible explanations for the rebound in employment from 1990 to 1993 include (a) increases in the mandatory retirement age and its spillover effects on older workers; (b) the government policy of subsidizing the hiring of older workers; (c) strong labor demand in the Japanese economy from the late 1980 s to the early 1990s, and (d) reforms in EP benefit rules. ${ }^{5}$

All of these factors are likely to increase the private-sector employment of men aged sixty to sixty-four. In fact, as shown in figure 9.2, the proportion of private-sector employment (wage and salary workers, excluding those who work on a temporary basis) among men in this age group in-

5. The EP benefit rule adopted in 1995 is expected to be less distortionary than the ones that preceded it. 


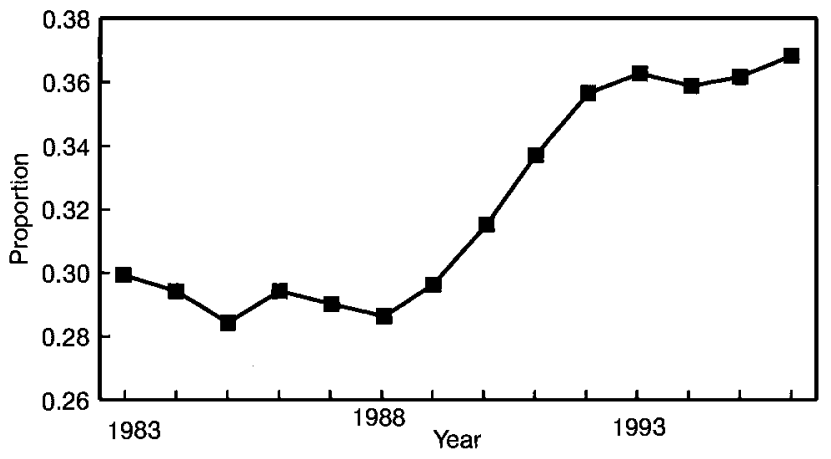

Fig. 9.2 Proportion of private-sector employment among men aged sixty to sixty-four

Source: Labor Force Survey, Statistical Bureau, Management and Coordination Agency, various years.

Note: The figure is (private-sector employed males aged sixty to sixty-four)/(total number of males aged sixty to sixty-four).

creased dramatically from 1988 to 1993 and continued to increase slightly until 1996. This rise occurred even though the overall labor force participation of the group declined between 1993 and 1996. The proportion of private-sector employment for men aged sixty to sixty-four rose from 30 percent in 1983 to 37 percent in 1996. The corresponding figures for the entire male population were 50 percent in 1983 and 53 percent in 1996; thus the increase in private-sector employment for the older group was higher than the economy-wide average. ${ }^{6}$ It is quite possible that while the recession of the mid-1990s reduced the number of older workers employed, there were offsetting institutional forces that contributed to an overall increase.

\subsubsection{Extension of the Mandatory Retirement Age}

The first such force may have been raising the mandatory retirement age. In many firms the mandatory age of retirement was raised gradually during the 1980s and 1990s, as shown in table 9.1. Large firms tended to raise it earlier than small or medium-sized firms. In 1992, for example, 95.2 percent of firms with more than 5,000 employees had a mandatory retirement age of sixty. This figure was 67.5 percent for firms with thirty to ninety-nine employees in 1992 and 73.6 percent in 1995. Some analysts have suggested that this change causes people aged fifty-five to sixty to work more hours, and to be more likely to work full time.

6. The comparable figure for men aged fifty-five to fifty-nine increased even more dramatically, from 47 percent in 1983 to 63 percent in 1996. A large part of this increase was probably due to the rise in the mandatory retirement age. 
Table 9.1

Distribution of Firms by Their Mandatory Retirement Age (percent)

\begin{tabular}{cccccc}
\hline & Below 55 & 55 & $56-59$ & 60 & Over 60 \\
\hline 1980 & 0.2 & 39.5 & 20.1 & 36.5 & 3.2 \\
1983 & 0.3 & 31.3 & 19.0 & 45.8 & 3.6 \\
1985 & 0.1 & 27.0 & 17.4 & 51.0 & 4.4 \\
1988 & 0.6 & 23.6 & 17.1 & 55.0 & 3.8 \\
1992 & 0.2 & 11.5 & 11.7 & 71.4 & 5.2 \\
1995 & 7.6 & & 6.6 & 78.6 & 7.2 \\
\hline
\end{tabular}

Source: Employment Management Survey (Koyo Kanri Chōsa).

\subsubsection{Government Subsidies for Hiring Older Workers}

The Japanese Ministry of Labor administers several programs to encourage companies to hire older workers. The programs include (a) a subsidy for introducing the practice of continuous employment for workers over age sixty-one (Keizoku Koyō Seido Donyū Shōrei-kin), (b) a subsidy for hiring a high proportion of older workers in the work force (Kōrei-sha Tasū Koyō Shōrei-kin), (c) a subsidy for introducing equipment suited to the needs of older workers (Kounenrei-sha Koyō Kankyō Seibi Shoreikin), and (d) a subsidy for offering paid holidays to workers who use them to improve their employment skills in their old age (Kōrei-ki Shūgyō Junbi Shōrei-kin). These subsidies are provided to employers who introduce systems that increase or facilitate the hiring of older workers. Furthermore, hiring greater numbers of older workers may entitle employers to additional subsidies. For example, they may qualify to receive the Subsidy for Employment Development for Special Workers (Tokutei Kyūsyoku-sha Koyō Shōrei-kin) by using public job-placement offices to hire workers aged fifty-five or older. All of these subsidies are financed by the Employment Insurance Account (the Japanese equivalent of unemployment insurance) ${ }^{7}$

\subsection{Benefit Reduction in Employees' Pension Insurance}

Until the year 2000, EP eligibles began receiving benefits at age sixty; the starting age for receiving EP is scheduled to rise gradually between 2001 and 2013 (for men). Under the reformed rules, EP eligibles aged sixty to sixty-four, as explained in note 2 , will receive only the part of the pension that is proportional to their lifetime EP contributions; they will not

7. In 1995, Employment Insurance started providing subsidies to older insured people who continue to work after age sixty (Kōrei-sha Koyō Keizoku Kyūfu). According to the Annual Report on Employment Insurance (Ministry of Labor 1995) the total amount paid through this system in 1995 was 10.9 billion yen (for seven months). The effect of this subsidy is not addressed in this paper, because the most recent data available are from 1992. 
receive the base benefits until they reach age sixty-five (Ministry of Health and Welfare of Japan 1996).

Any model of the effect of EP benefit reduction on working beneficiaries must consider three decisions a covered person must make. The first, the application decision, is whether (and when) to apply for EP benefits sometime after the age of sixty. The second is the work-mode choice, since the benefit reduction scheme treats different types of jobs very differently. The final decision relates to the number of hours the worker chooses to work. The sequence of decisions described below is illustrated in figures 9.3 and 9.4.

\subsubsection{Application Decision}

As explained in note 3, application for determination of entitlement (saitei) by the covered individual is the necessary precondition for receiving EP benefits. A sizable proportion of qualified individuals (potential EP eligibles) does not file for EP benefits at age sixty. Based on a crosssectional calculation from the 1992 Annual Report of the Social Insurance

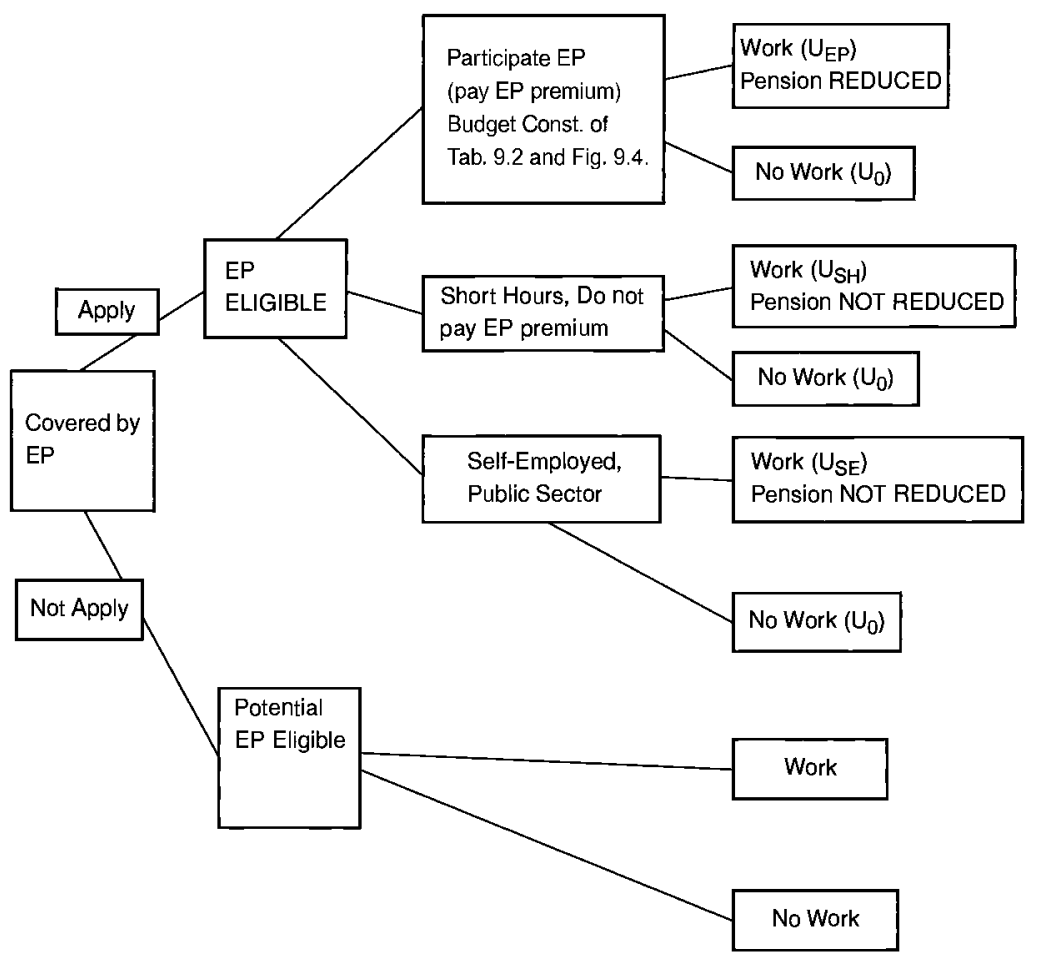

Fig. 9.3 Work-hours decision for male worker aged sixty to sixty-four by Employees' Pension 


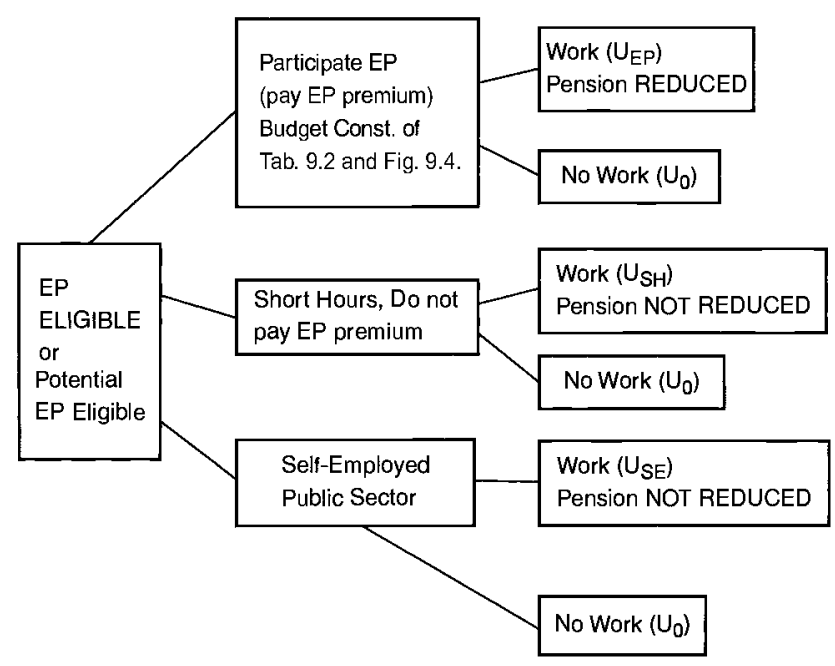

Fig. 9.4 Work-hours decision for Employees' Pension eligible or potential eligible male worker aged sixty to sixty-four

Agency, only about 57 percent of covered males apply at age sixty. About 21 percent apply between the ages of sixty-one and sixty-four, and most of the remainder apply at age sixty-five. Only 3 percent apply after age sixty-six.

The fact that less than 60 percent of covered individuals apply at the earliest possible age (sixty) is somewhat surprising. Because EP benefits are affected by the number of years a worker contributes to the program, some may want to increase their benefits by extending the period of contribution. Moreover, a delayed application does not cause a loss in cumulative benefits, because benefits for up to the five years preceding the application are paid once a worker's entitlement has been determined. Since most people file by the age of sixty-five, the only loss caused by a late application is the interest that workers could earn on the benefits due to them from the age of sixty. ${ }^{8}$ It is likely that covered individuals who do not apply at age sixty face no liquidity constraints and choose to work. In that sense, the application decision and the decision to participate in the labor market are very closely related, and both should be treated as endogenous.

Although the SECOP data sets do not ask specifically about application status, the sample includes many male workers aged sixty to sixty-four who were employed in the private sector at age fifty-five (and so are likely

8. Because the past benefits paid at the time entitlement is determined (after age sixty) are the sum of past benefits, late application results in the loss of interest that might have accrued if the determination had taken place earlier. If a covered individual faces liquidity constraints after age sixty, therefore, it does not make sense to delay application. 
to be covered by the EP) and who receive no EP benefits between sixty and sixty-four. Such individuals either have not filed the application for EP benefits or have filed but have incomes too high to receive benefits. The SECOP data sets do not allow me to distinguish between these two cases precisely. However, the number of people who can be put in either of these categories is much higher than the estimated number of those in the second category, which can be calculated by using the published data in the Annual Report of the Social Insurance Agency. This fact suggests that it is important to consider the possibility of nonapplication in analyzing the effects of benefit reductions on the labor supply of men in this age group.

\subsubsection{Work-Mode and Hours Decisions}

The second decision individuals must make concerns the mode and hours of work. As noted earlier, working EP eligibles aged sixty to sixtyfour, who are wage or salary workers in the private sector and who work more hours than three-quarters of the firm's regular workers must participate in EP (i.e., must pay EP premiums out of their current earnings) until they reach age sixty-five. Under the EP benefit reduction scheme, the benefits received by EP an participant aged sixty to sixty-four depends on the level of employment income: An increase in employment income is "taxed" by a reduction in EP benefits.

The reduction rules for the years I analyze in this paper-1983, 1988, and 1992 - are shown in table 9.2, which also explains the rule in effect after April 1995 under the reformed EPIA of 1994. Before 1995, there were many more "notches" in the budget constraints, which are likely to affect EP eligibles' decisions about the trade-off between consumption and leisure. There were four such notches until 1989, and eight between 1989 and 1995. Even after the 1994 reform, one notch still remained: the one at the margin between work and no work. Overall, from 1983 to 1995 the rule changed in the direction of encouraging participation in the labor force. The typical budget constraints in 1983, 1992, and 1995 are shown in figure 9.5. ${ }^{9}$ The complicated benefit rule put into effect in 1992 increased disposable incomes in the intermediate range of the budget constraint compared with the situation before 1989. The 1994 reform eliminated most notches.

From 1986 to 2001, EP benefits are reduced for EP eligibles aged sixty to sixty-four, while those sixty-five or over receive full EP benefits regardless of their labor income. ${ }^{10}$ However, until 1986, benefit reduction was

9. The graphs incorporate the following set of parameters: wage, 800 yen per hour; potential EP benefits, 180,000 yen per month; living with spouse, no dependents. Continuing to make contributions to EP between ages sixty and sixty-four increases future benefits, but this aspect is ignored in these figures.

10. Starting April of 2002, EP benefit reduction is going to be applied to EP eligibles aged sixty-five to sixty-nine, as well as those aged sixty to sixty-four. 


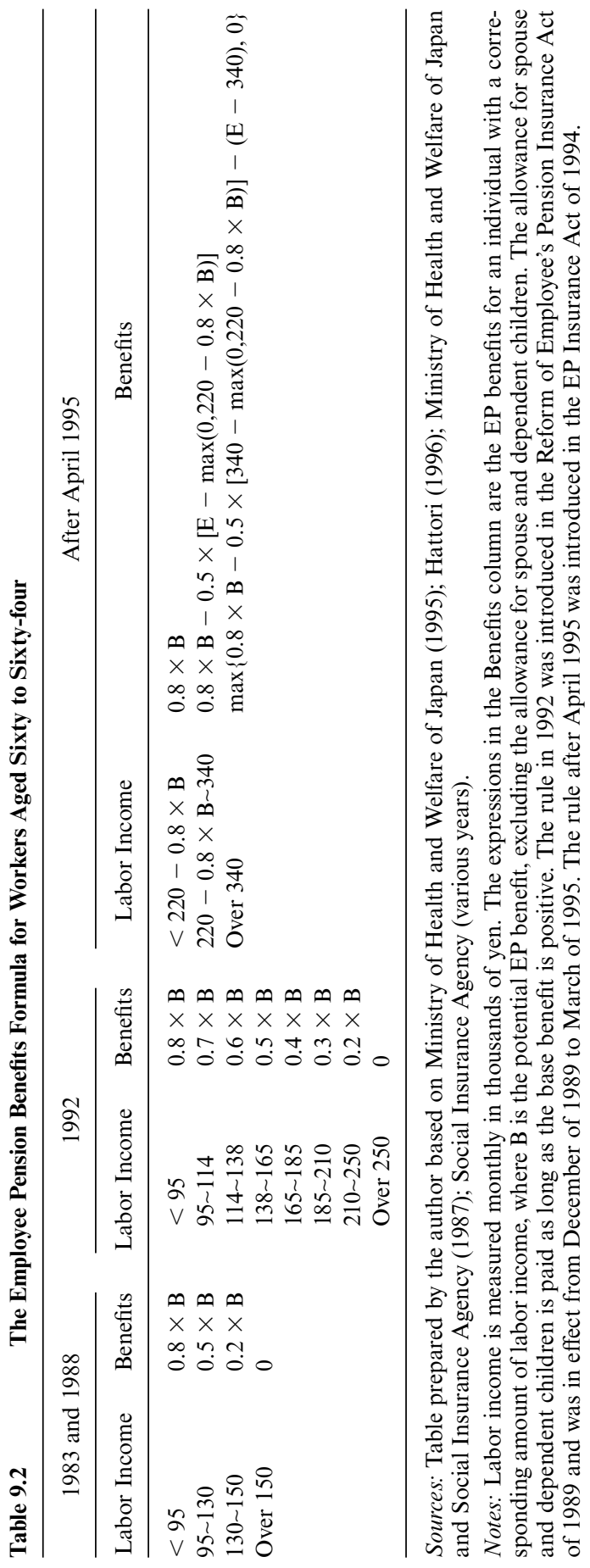



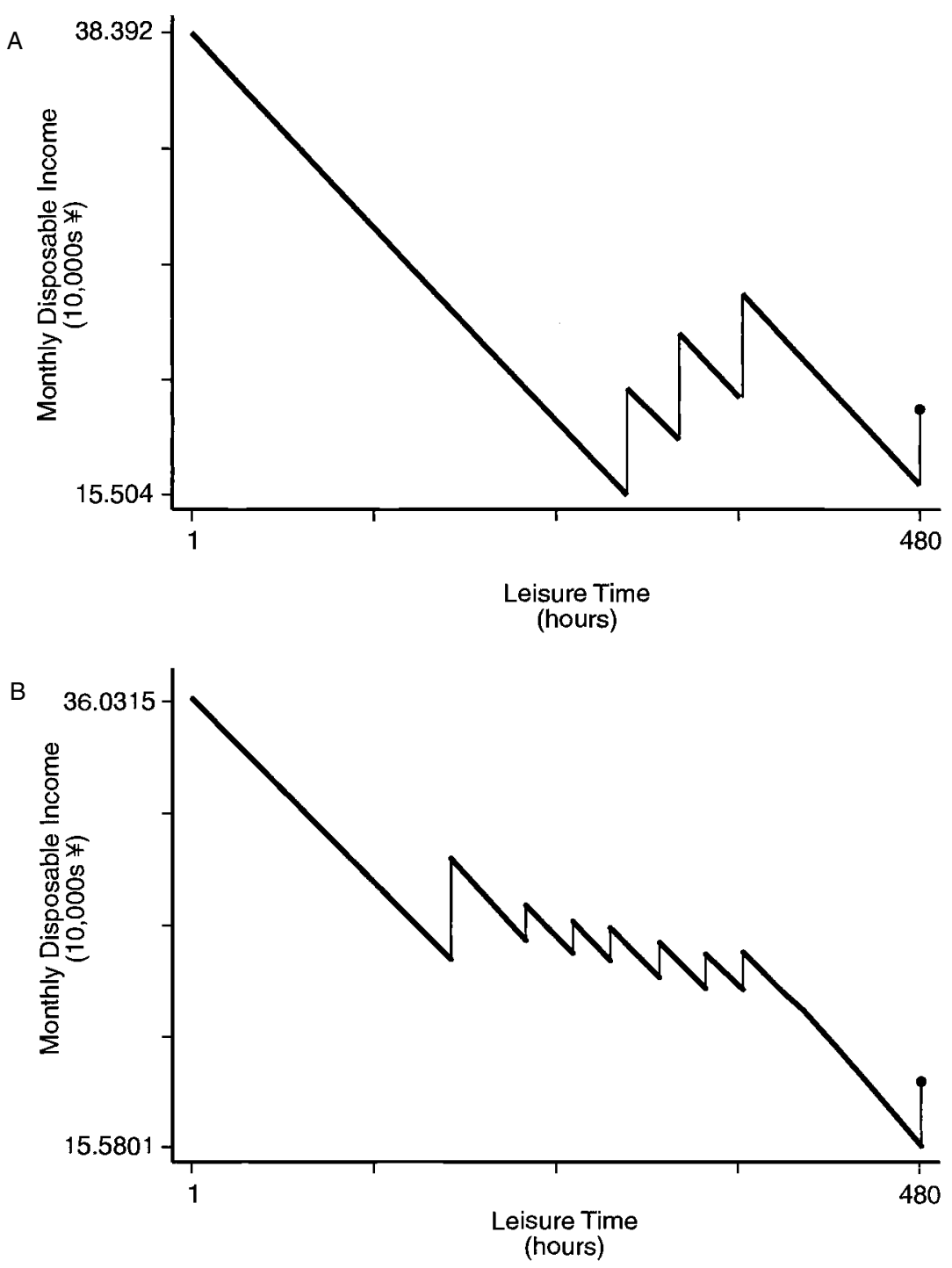

Fig. 9.5 Budget constraint, with spouse (wage $=800$ yen/hour): $(A), 1983$ and 1988; (B), 1992; $(C), 1995$

also applied to those aged sixty-five or over. Before April 1986, EP benefits for those aged sixty-five or over with earnings of more than 160,000 yen (per month) were reduced by 20 percent. This rule was more generous than the one applied to workers sixty to sixty-four years old, who received no benefits at all for the same level of labor income. Thus the pre-1986 




Fig. 9.5 (cont.)

rule seems likely to have encouraged work among men aged sixty-five or over, while discouraging it for those aged sixty to sixty-four.

The work-mode choices shown in figure 9.3 are (a) participating in EP, (b) working part time and not participating in EP, and (c) being selfemployed and not participating in EP. In each work mode, a worker decides on working hours according to the budget constraint applicable to that particular mode. In the EP-participation mode, for example, the applicable budget constraint is shown in figure 9.5. In the part-time mode, limiting hours to less than three-quarters of those worked by regular workers produces no cut in benefits; in the self-employed mode, there are no benefit cuts at all. Employees' Pension eligibles aged sixty to sixty-four solve the problem in the following way. They first determine the maximum utility of each work-mode option, then compare the utilities and choose the mode that yields the highest utility. Since the budget constraints for different work modes are different, we need to identify each worker's chosen work mode.

The budget constraints applicable to potential EP eligibles are similar to those for EP eligibles. Assuming that covered individuals file their applications by age sixty-five, they can, as noted earlier, collect the benefits they would have received between the ages of sixty and sixty-four. The amount of benefits paid for those years will depend on the employment income earned. For example, if an individual's earnings at age sixty-two are positive, then the benefits corresponding to that year are cut based on the earnings of that time (at age sixty-two). Therefore, the amount the worker 
receives for past benefits after his or her entitlement is adjusted according to the labor income earned before filing the application. Thus, as far as choice of work mode and hours are concerned, EP eligibles and potential EP eligibles are in a similar situation. ${ }^{11}$ For this reason, I consider them as one group when I analyze workers' labor-supply decisions, as illustrated in figures 9.3 and 9.4 .

\subsubsection{Identifying Chosen Decisions in the Data Set}

The institutional structure discussed above must be incorporated into any model for analyzing the effects of the EP benefit reduction scheme. However, the SECOP data sets contain several ambiguities that make identifying the decisions made by individual workers difficult. First, the survey does not ask respondents whether they have already filed the application for EP benefits. Second, it does not ask whether they participate in EP. The question on current employment status does allow us to identify those who are currently self-employed or who work in other modes that do not require EP participation. It remains difficult, however, to identify the application status and EP-participation status of those employed in the private sector. The main reasons for the difficulty are that (a) part-time, private-sector workers may or may not participate in EP, and (b) EP benefits for high-income EP eligibles are cut to zero, so that these eligibles are indistinguishable from workers who are not EP eligible. There is some evidence that a sizable proportion of male part-time workers do not participate in EP, as the following analysis shows.

\subsubsection{Evidence on Employees' Pension Participation}

The administrative statistics of the Social Insurance Agency indicate how many EP eligibles actually receive reduced EP benefits. Until 1994, around 20 percent of male EP eligibles aged sixty to sixty-four (those who applied for EP benefits after age sixty) worked, participated in EP, and received reduced or zero benefits. That proportion rose to 28 percent in 1995 , the year in which both the 1994 EPIA reform and Employment Insurance employment-continuation benefits for workers aged sixty to sixty-four were put into effect (see table 9.3). ${ }^{12}$ These changes made working in the private sector more attractive for older people and so are likely to have increased EP participation among EP eligibles.

The figures, however, are much lower than the 1994 Labor Force Survey's proportion of private-sector employment, which was 36 percent. Since the data in the Labor Force Survey are based on the entire population and not on EP eligibles alone, part of the discrepancy may be attribut-

11. It is important to keep in mind that the potential EP eligibles are not included in some of the governmental statistics on EP eligibles.

12. Under the employment-continuation benefit, older workers who experience large wage decline can receive wage subsidy. 
Table 9.3

Employees' Pension Participation and Benefit Reduction among Those Eligible, Aged Sixty to Sixty-Four

\begin{tabular}{ccc}
\hline & $\begin{array}{c}\text { EP Participation } \\
\text { and } \\
\text { Benefit Reduction }\end{array}$ & $\begin{array}{c}\text { EP Participation } \\
\text { and Benefit Reduction } \\
\text { and Benefit }>0\end{array}$ \\
\hline 1992 & 0.231 & 0.210 \\
1993 & 0.224 & 0.203 \\
1994 & 0.209 & 0.189 \\
1995 & 0.284 & 0.227 \\
\hline
\end{tabular}

Source: Numbers of EP eligibles (i.e., denominators) are from the Social Insurance Agency's annual report: the 1992 number is from the 1992 report (published in 1994); 1993 numbers, the 1995 report; 1994 numbers, the 1996 report; and 1995 numbers, the 1997 report. Numbers for EP participation and benefit reduction (i.e., numerators) are from Summary of the Social Insurance Policy (1995).

Notes: The figures are calculated as the number of those who received reduced benefits or zero benefits (due-to-the-means test) out of the total number of male EP eligibles aged sixty to sixty-four. The potential EP eligibles, who have not yet applied for EP benefits, are excluded from both the numerator and the denominator.

Basically, the EP benefit reduction applies only to workers sixty to sixty-four years old. However, there are rare cases in which people aged sixty-five or more face the benefit reduction, because of the transitional arrangements. Since the Social Insurance Agency does not publish the number of sixty- to sixty-four-year-old EP participants classified by sex, the numerator of the calculation for 1992-95 is slightly larger than the actual number of male EP participants in that age group.

able to differences in the labor supply behavior of EP eligibles and others. However, the differences also could be attributable to two other factors: (a) nonapplication to the EP by qualified individuals at age sixty, and (b) nonparticipation by EP eligibles who work part time. Potential EP eligibles are more likely to work than EP eligibles; thus the probability that EP eligibles work is likely to be lower than the one calculated for a group that also includes potential EP eligibles. ${ }^{13}$ When EP eligibles work part time and choose not to participate in EP, neither they nor their employers are required to pay the EP premium. In addition, EP eligibles who work part time receive full benefits, but they lose the opportunity to increase their future EP benefits through a longer period of contribution.

The EP-participation decision may also be influenced by the worker's desire to participate in an employer-provided health insurance plan. ${ }^{14}$

13. Probability of working - that is, the ratio of the number of people who worked to the population as a whole - is used as one measure of labor supply in this paper. It differs from labor force participation, which includes unemployed workers in the numerator. The SECOPIP questionnaire does not specifically ask people whether they have searched for jobs in a given period, which is part of the standard definition of unemployment.

14. There is a significant variation in the National Health Insurance premium across municipalities. Furthermore, employer-provided health insurance is more generous in benefits than National Health Insurance and allows the insured to cover family members at no additional cost. Therefore, if the National Health Insurance premium is high in an area or the 
Table 9.4

Proportion of Participation in Employees' Pension and EmployerProvided Health Insurance

\begin{tabular}{ccc}
\hline & Short Hours & Long Hours \\
\hline Male (\%) & & \\
1990 & 19.5 & 69.0 \\
1995 & 36.5 & 79.0 \\
Female (\%) & & \\
1990 & 24.8 & 71.9 \\
1995 & 35.6 & 78.1 \\
\hline
\end{tabular}

Source: Ministry of Labor $(1992,1997)$.

Since the criteria for participating in EP and participating in employerprovided health insurance are the same for those aged sixty-four or younger, it is difficult to enroll in an employer's health plan without also participating in EP. Thus a part-time worker who strongly prefers the employer-provided health insurance to the National Health Insurance might choose to participate in EP even though that requires payment of the EP premium and, possibly, reduces EP benefits.

Table 9.4 lists the summary statistics on EP participation and employerbased health insurance coverage from the Ministry of Labor's General Survey of Part-Time Workers (GSPTW) for 1990 and 1995 (see Ministry of Labor 1992, 1997). These statistics are calculated for part-time workers of all ages and not solely for the EP-eligible workers aged sixty to sixtyfour. ${ }^{15}$ In 1990, almost 20 percent of male workers who worked fewer hours than regular employees participated in EP and received health insurance provided by the employer; that figure increased to 37 percent in 1995 . Furthermore, 20 to 30 percent of male part-time workers who worked as many hours as regular workers did not participate in EP. Although these figures are only indirect evidence of EP participation by male EP eligibles in the sixty- to sixty-four-year-old age group who work part time, they suggest that it is probably misleading to assume either that no part-time workers participate in EP or that all of them do.

\subsection{Data Description}

I turn now to an analysis of the EP benefit reduction scheme and its effect on the male labor supply of Japan, using the microdata sets of the Survey on Employment Conditions of Older Persons for 1983, 1988, and 1992. The SECOP consists of two surveys, one for individuals and the

worker has family members to insure, it makes more sense to participate in employerprovided health insurance.

15. As the survey questionnaire of GSPTW does not ask about the public pension under which an individual is covered, it is difficult to identify EP eligibles. 
other for establishments. ${ }^{16}$ The Individual Persons file (IP), a crosssectional survey of individuals between the ages of fifty-five and sixty-nine, asks for detailed information on employment, labor income, pension type and amount received, nonlabor income, work history, and household characteristics. ${ }^{17}$ The variables used in the analysis are explained below. ${ }^{18}$

\subsubsection{Employees' Pension Eligibility}

To analyze the effects of EP benefit reduction on labor supply, we need to identify the type of public pension covering each individual. The 1983 IP survey questionnaire asked respondents directly about their eligibility for a public pension. The questionnaires for 1988 and 1992, however, inquired about the amount of EP benefits received but did not ask specifically about eligibility. Obviously, those who received positive EP benefits were EP eligibles. The ambiguity arises from two other groups: The first group includes covered individuals who do not apply for EP benefits at age sixty but remain potential EP eligibles; the second group contains EP eligibles whose benefits are cut to zero because their labor income is too high (see table 9.2). According to the Annual Report of the Social Insurance Agency (1992), about 9 percent of EP eligibles who work and participate in EP receive no EP benefits for this second reason. As mentioned in the preceding section, the economic conditions for potential EP eligibles who work and for EP eligibles who receive zero benefits are similar, so I assume that both of them belong to the EP group. In the following discussion, therefore, I try to draw from the IP data set the combined number of potential EP eligibles and EP eligibles whose EP benefits are cut to zero.

There is no direct way to identify these two groups in the IP data set for 1988 and 1992. Therefore, following a procedure similar to the one employed by Ogawa (1997), I assume that a person with the following set of characteristics is an EP eligible, even though he received zero EP benefits: (a) He worked more than thirty-two hours per week; (b) his labor income

16. The establishment survey of the SECOP asks detailed questions about the number of older workers employed and the employment status of such workers in the organization.

17. Seike and Shimada (1994) based their analysis on the SECOP-IP data set for 1983; Tachibanaki and Shimono (1985) and Amemiya and Shimono (1989) used the data set for 1980; and Ogawa (1997) used 1983, 1988, and 1992 data sets.

18. In this study, I include people who answered no to the question "Were you an employee when you were 55?" This sample selection differs from that used by Seike and Yamada (1996), who included only those who answered yes to this question. Many individuals who answered no did in fact work at a later stage in life and, in 75 percent of such cases, they were selfemployed. What is likely to have happened is that they became self-employed before age fiftyfive and continued to be self-employed thereafter. Because the questionnaire asks whether the respondent was "an employee" at age fifty-five, some of the self-employed people may have answered no. Self-employed individuals can receive EP benefits if they participated in the EP sometime during their working lives. In fact, 16 percent of the sixty- to sixty-nine-yearold males who answered no to the question and were working at the times of the surveys received positive EP benefits. 
was higher than the threshold at which EP benefits were reduced to zero; (c) he worked in the private sector as an employee at the time of the survey; (d) he worked in the private sector at age fifty-five; (e) he did not receive high benefits (more than 50,000 yen per month) from a Mutual Aid Association (MAA) pension program; and (f) he was between sixty and sixtyfour years old. Criteria (a) and (c) ensure that the person makes EP contributions out of current labor income, which is a precondition for reductions in EP benefits. I assign a person who meets criteria (a), (c), (d), and (f) to the potential EP-eligible category if his receipts from all public pension programs are zero. ${ }^{19}$ The idea behind this last condition is that if a person had claimed benefits from any of the public pension programs to which he contributed in the past, he probably would have applied for EP benefits as well.

The assignment of EP eligibility (including potential EP eligibility) in this way creates a sample EP group in which 15 percent of the observations receive zero benefits. This rather high proportion is understandable if it is caused by nonapplication. ${ }^{20}$ Nonetheless, the procedure described above may cause one to classify someone who is unrelated to EP as an EP eligible or a potential EP eligible. For this reason, I base the analysis in this paper on two separate samples. Sample 1 includes all EP eligibles and potential EP eligibles as explained above. Sample 2 includes EP eligibles who receive positive EP benefits but excludes those who either (a) receive zero benefits because their labor income is too high, or (b) are potential EP eligibles who do not seem to have applied to EP benefits even though they are likely to have contributed to EP. Sample 1 might contain some non-EP individuals who are misclassified as EP eligibles (or potential EP eligibles). Sample 2 is likely to be free from classification errors but is a biased sample because it excludes those who endogenously choose to earn high income or choose not to apply for EP benefits. ${ }^{21}$

\subsubsection{Pension Income}

The IP questionnaire asks for the amount of pension benefits received by an individual from particular types of pension. The categories are EP (benefits given separately for working beneficiaries and others), National Pension (NP), Mutual Aid Association (MAA), company-provided pen-

19. The reasons for imposing conditions (a) and (c) for identifying potential EP eligibles are weak. I also experimented with a sample by dropping these conditions in assigning potential EP eligibles and found that some of the results are sensitive to such differences.

20. In fact, of those individuals I assigned to the nonapplication category, 33 percent are sixty years old and only 12 percent are sixty-four. (Note that I assigned only those aged sixty to sixty-four.) This pattern is consistent with the finding that more people finish their EP application as they get older.

21. Note that Sample 1 includes more workers than Sample 2 does. This is because men excluded from Sample 2 but included in Sample 1 are those who work. Sample 2 is a biased sample, but whether Sample 1 includes the "right" number of workers is not clear. 
sions, and others (including private pensions purchased by the respondent). The EP benefits consist of the basic part and allowances for spouse and dependent children. The basic part is the sum of base benefits and the earnings related part. The amount of the latter is proportional to the individual's lifetime EP contributions. The allowances are not cut as labor income increases unless the benefits from the basic part become zero. When the worker's labor income hits the highest threshold for reduction (250,000 yen in 1992), the allowances for spouse and dependent children are eliminated. Since the amounts of the allowances for spouse and dependent children are not recorded in the data set, I base my analysis solely on the reported EP benefits for the basic part. ${ }^{22}$

The actual amount of pension received (asked in the IP survey) is not equal to the potential amount because the former is adjusted depending on labor income. Since the survey did not ask respondents how much they would receive if they were not working (potential EP benefits), that amount must be estimated. Ogawa (1997) developed the method to do this, which I have basically followed for determining the amount of an individual's potential EP benefits. For individuals whose labor income is high enough to cut EP benefits to zero, I have assigned a potential amount that is the mean value of nonworking individuals who receive EP benefits in full and have similar characteristics (in terms of birth year and occupation at age fifty-five or at retirement).

\subsubsection{Weekly Hours}

As the IP questionnaire asks separately about working hours per day and working days per week, I multiply the two figures to obtain hours of work per week. For a typical answer of eight hours per day and six days per week, I assign the number of weekly hours as forty-four, because one of the six working days is likely to be a half day. I eliminate weekly hours above seventy from the sample, since such figures are likely to be outliers for older workers.

\subsubsection{Household Characteristics}

The IP survey asked three questions related to household characteristics: (a) the number of people in the household, (b) the number of working individuals in the household, and (c) the respondent's main source of income. Following earlier researchers, I assume that respondents belong to one of the following five household categories: (a) single, one individual living alone; (b) couple, a two-person household in which the respondent is supported by himself or by his spouse; (c) living with dependent children,

22. It is difficult to arrive at any approximate figure for allowances without information on the characteristics that determine eligibility for allowances (e.g., age and/or income of spouse or children). 
a household consisting of more than three individuals in which the respondent is self-supporting or is supported by his spouse; (d) supported by children, a household that consists of more than two individuals with the respondent is supported by his children; and (e) none of the above.

\subsection{Descriptive Statistics from the SECOP-IP}

The labor force participation statistics I cited earlier in the paper are based on the entire population of men aged sixty to sixty-four. The SECOP-IP data sets, however, allow me to compare the effects on labor supply of people covered by different public pension programs (in particular, EP and non-EP programs). As explained above, I use two samples to check for possible classification errors. Sample 1 includes EP eligibles and potential EP eligibles; Sample 2 excludes some of the EP eligibles and potential EP eligibles included in Sample 1.

Table 9.5 organizes the four measures of labor supply of men I derived from the SECOP-IP data according to the type of public pension received (EP and non-EP). For each age group the measures describe (a) the pro-

Labor Supply of Men Aged Fifty-Five to Sixty-Five, 1983-92

\begin{tabular}{|c|c|c|c|c|c|c|}
\hline & \multirow{3}{*}{$\begin{array}{c}55 \leq \\
\text { Age } \leq 59\end{array}$} & \multicolumn{3}{|c|}{$60 \leq$ Age $\leq 64$} & \multirow{2}{*}{\multicolumn{2}{|c|}{ Age $\geq 65$}} \\
\hline & & & FP & & & \\
\hline & & (Sample 1) & (Sample 2) & NonEP & EP & NonEP \\
\hline \multicolumn{7}{|c|}{ Percentage worked } \\
\hline 1983 & 0.862 & 0.539 & 0.466 & 0.777 & 0.484 & 0.602 \\
\hline 1988 & 0.898 & 0.627 & 0.449 & 0.701 & 0.430 & 0.614 \\
\hline 1992 & 0.938 & 0.668 & 0.505 & 0.737 & 0.504 & 0.621 \\
\hline \multicolumn{7}{|c|}{ Percentage employed } \\
\hline 1983 & 0.590 & 0.367 & 0.274 & 0.346 & 0.326 & 0.167 \\
\hline 1988 & 0.645 & 0.487 & 0.243 & 0.256 & 0.250 & 0.198 \\
\hline 1992 & 0.672 & 0.538 & 0.312 & 0.296 & 0.326 & 0.222 \\
\hline \multicolumn{7}{|c|}{ Percentage full-time } \\
\hline 1983 & 0.779 & 0.419 & 0.327 & 0.601 & 0.364 & 0.408 \\
\hline 1988 & 0.781 & 0.484 & 0.238 & 0.444 & 0.252 & 0.369 \\
\hline 1992 & 0.861 & 0.545 & 0.321 & 0.495 & 0.301 & 0.387 \\
\hline \multicolumn{7}{|c|}{$\begin{array}{l}\text { Average weekly hours } \\
\text { of working } \\
\text { individuals }\end{array}$} \\
\hline 1983 & 44.13 & 39.63 & 37.55 & 42.00 & 39.11 & 38.67 \\
\hline 1988 & 43.47 & 39.34 & 32.44 & 37.11 & 33.80 & 35.87 \\
\hline 1992 & 43.87 & 40.04 & 35.58 & 38.43 & 33.82 & 36.44 \\
\hline
\end{tabular}

Source: Author's calculation from Survey on Employment Conditions of Older Persons (SECOP), 1983, 1988, and 1992.

Note: Sample 1 contains individuals who receive no EP benefits but are likely to be EP eligibles or potential EP eligibles; Sample 2 excludes them. 
portion working, (b) the proportion employed in the private sector as wage or salary earners, (c) the proportion working full time (thirty-five hours or more per week), and (d) the average number of hours worked per week calculated among workers. I distinguish between the percentage of working and the percentage of those employed in the private sector because EP benefit reduction applies only to EP eligibles in the private sector. Reflecting the fact that the mandatory retirement age was raised from fifty-five to sixty, the proportion of men working in this age group increased between 1983 and 1992. For non-EP individuals sixty to sixty-four years old, the proportion decreased from 1983 to 1988 and then increased. For the combined group of EP eligibles and potential EP eligibles (Sample 1), the percentage working increased steadily from 1983 to 1992 . On the other hand, the proportion of those working in the subsample of EP eligibles (Sample 2) decreased from 1983 to 1988 and then increased in 1992. In most categories, the number of hours worked decreased and then increased during this time period.

The 1983, 1988, and 1992 distributions of work hours for sixty- to sixtyfour-year-old men, classified by public pension types (EP group includes potential EP eligibles), are shown in figures 9.6 to 9.11. The numbers for all groups and all years show the largest clusters of work hours at the points for no work and full-time work. The graphs indicate clearly that EP eligibles are less likely to work than others, but also that a larger proportion of EP eligibles worked in 1992 than before that time.

The Japanese government has recently adopted policies to shorten the maximum regular working hours of workers in the Japanese labor mar-

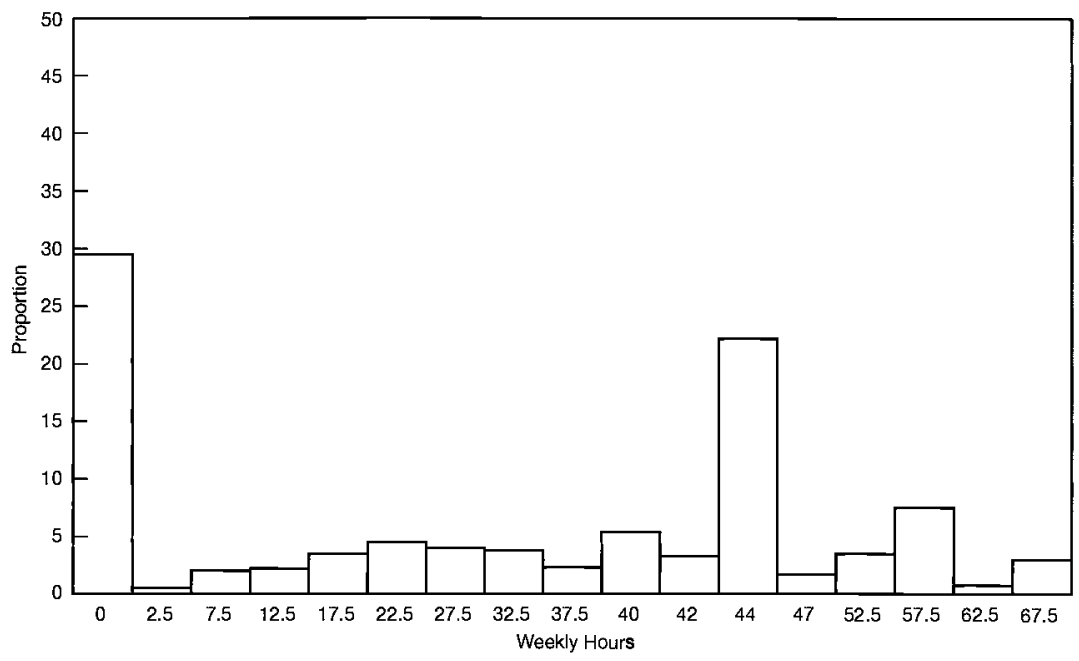

Fig. 9.6 Employees' Pension noneligible men, 1983 


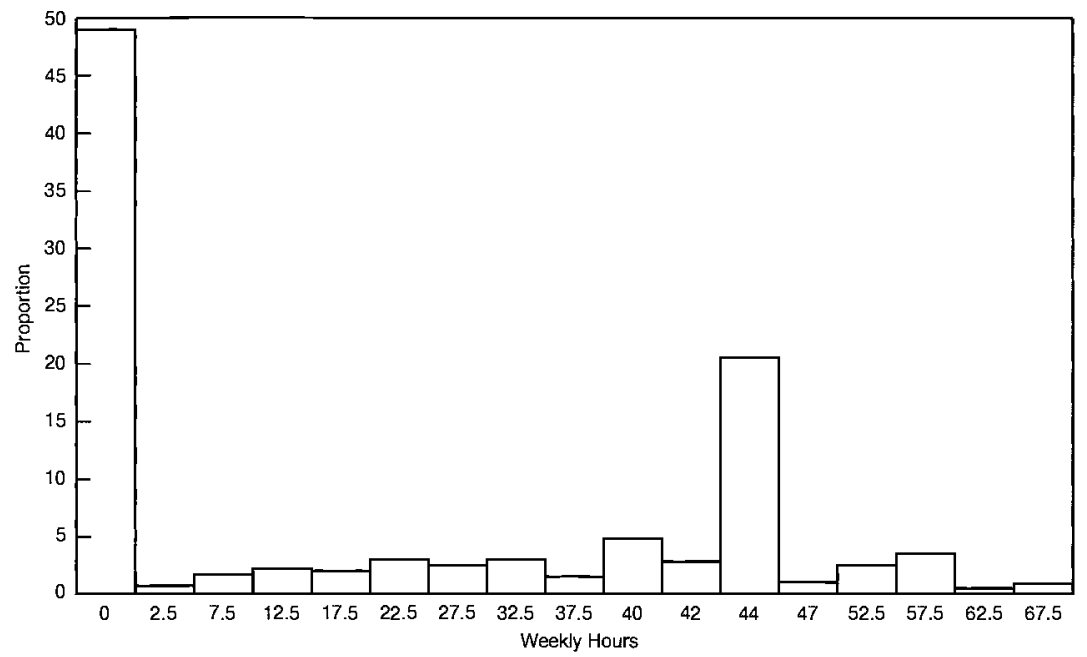

Fig. 9.7 Employees' Pension eligible men, 1983

ket. ${ }^{23}$ Beginning in April 1997, the legal maximum was forty hours per week for all employers. According to the General Survey on Wages and Working Hours System of the Ministry of Labor (various years), the proportion of firms with regular work weeks of forty hours or less was 14.8 percent in 1980, versus 35 percent in 1992. The same trend is discernible in the proportion of firms with more than forty-four regular working hours, which declined from 54.6 percent in 1980 to 21.9 percent in $1992 .{ }^{24}$ While the legal maximum on work hours applies to workers of all ages, this change in policy clearly has affected the hours-distribution of older workers. As shown in figures 9.8 through 9.11, the proportion of older workers working forty-four hours or more declined between 1988 and 1992 and the proportion of those working forty hours increased.

\subsection{Reduced-Form Analysis of Male Labor Supply}

I turn next to a reduced-form regression analysis of labor supply. The regression equation I estimate has the form

23. The restriction was first applied to large firms or growing industries and was later applied to smaller firms.

24. These figures are based on the weekly hours applied to most of a firm's employees. Increases in the number of part-time workers, therefore, are not likely to affect this figure even though that would make average hours of work smaller. The same figure weighted by the number of employees also appears in the survey; it shows a rise in the number of those working forty hours or less per week from 45.3 percent in 1980 to 67.4 percent in 1992. 


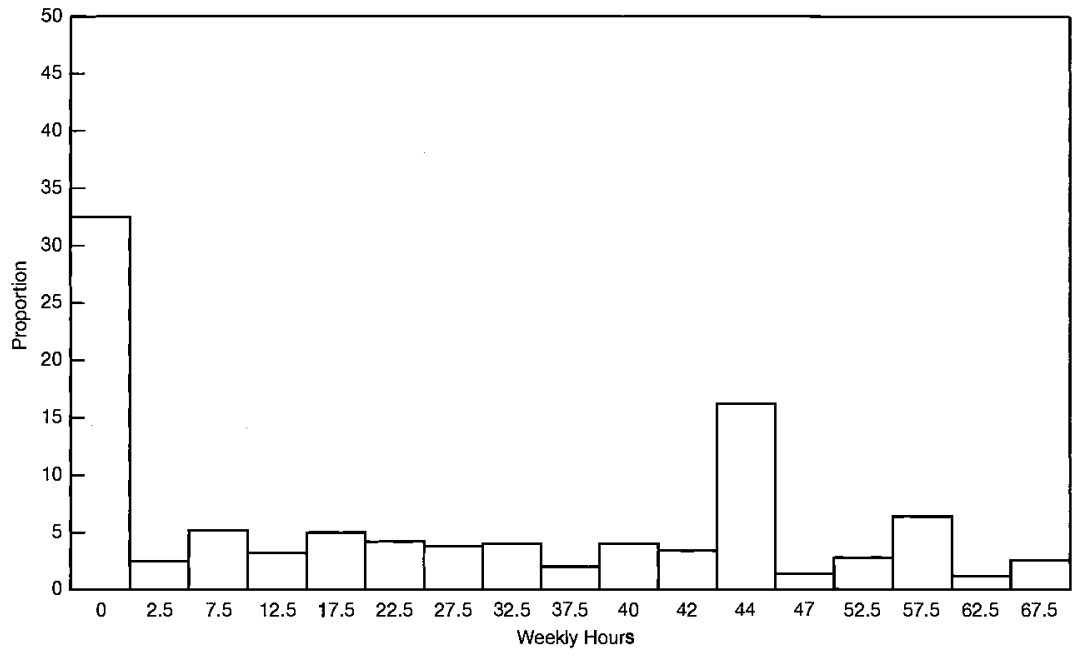

Fig. 9.8 Employees' Pension noneligible men, 1988

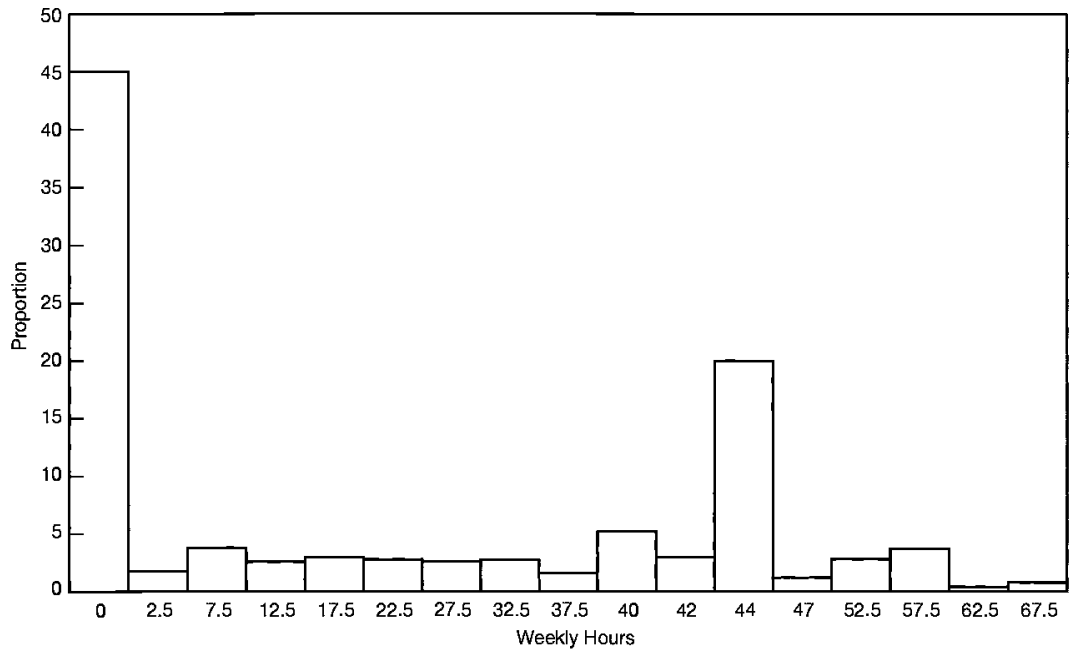

Fig. 9.9 Employees' Pension eligible men, 1988

$($ Worked or Employed $)=\operatorname{Probit}\left[\alpha_{1}(\right.$ Year Dummies $)$

$+\alpha_{2}($ Year Dummies $\times$ Age60-64)

$+\alpha_{3}$ EP Eligibility $+\alpha_{4}($ EP Probability $\times$ Age60-64 $)$

$+\alpha_{5}($ EP Eligibility $\times$ Age60-64 $\times$ Year Dummies $)$

$+\alpha_{6}($ EP Eligibility $\times$ Age65over $\times$ Year1983 $+\mathrm{X}]+\varepsilon$, 


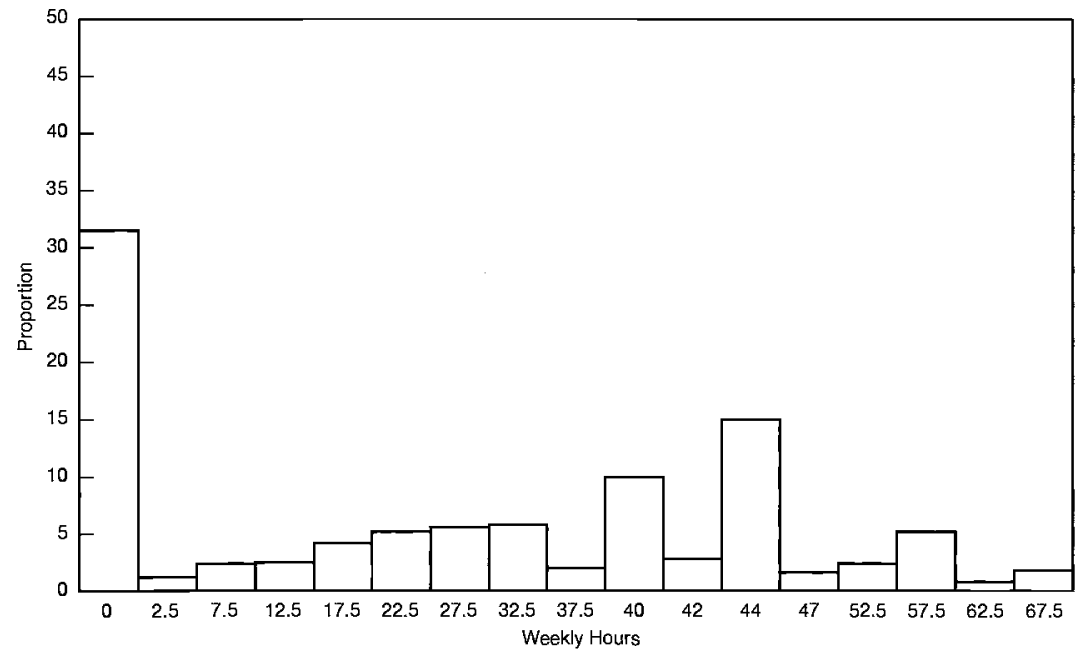

Fig. 9.10 Employees' Pension noneligible men, 1992

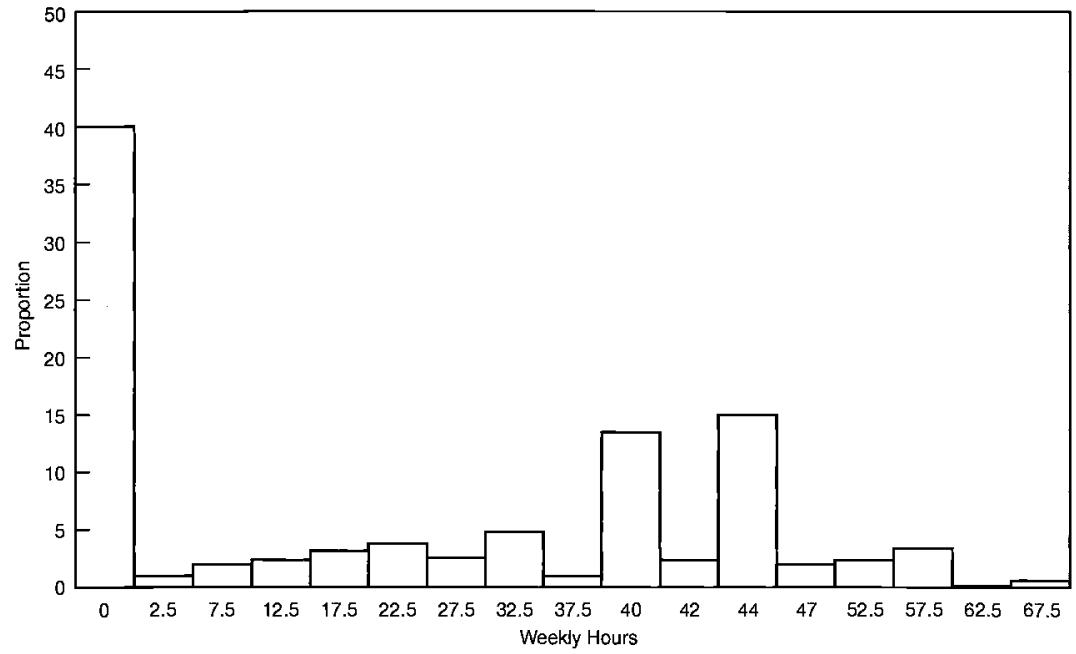

Fig. 9.11 Employees' Pension eligible men, 1992

$\log ($ Weekly Hours $)=\beta_{1}$ (Year Dummies $)$

$+\beta_{2}\left(\right.$ Year Dummies $\times$ Age60-64) $+\beta_{3}$ EP Eligibility

$+\beta_{4}($ EP Eligibility $\times$ Age60-64)

$+\beta_{5}($ EP Eligibility $\times$ Age60-64 $\times$ Year Dummies $)$

$+\beta_{6}($ EP Eligibility $\times$ Age65over $\times$ Year1983 $)+X+\varepsilon$. 
The dependent variables are likelihood of working, likelihood of privatesector employment as a wage or salary earner, and weekly hours. Hours equations are estimated for each sample of workers or employees. The analysis of private-sector employment is included because EP benefits are cut only if an EP eligible works as a wage or salary earner in the private sector. Because the EP benefits formula for working beneficiaries changed in 1989, I was able to use the available data to compare labor supply outcomes before and after the policy change.

The summary statistics in table 9.5 show that the probability of working for EP eligibles aged sixty to sixty-four (the group affected by the policy change) increased from 1988 to 1992, although that probability rose for non-EP beneficiaries (i.e., the control group) as well. The interaction term of EP eligibility, age sixty to sixty-four, and the year dummy for 1992 reveals the effect of the policy change on EP eligibles (i.e., the treatment group). In addition, as noted earlier, in 1983 EP benefit reduction also applied to EP eligibles aged sixty-five or over, although the benefit schedule used was different from that applied to the sixty- to sixty-four-year-old group at any time. To extract the change in labor supply behavior by the group affected by the 1989 EPIA reform, I include a set of interaction terms of EP eligibility, age-category dummy, and year dummies. There are eleven such interaction terms. The set of control variables includes dummies for household characteristics, a dummy variable for having experienced mandatory retirement, a dummy for not being an employee at age fifty-five, a dummy for living in Tokyo, a health-status dummy, the amount of public pension received (the potential amount for EP eligibles), the amount of company pension receipt, a dummy variable for MAA pension beneficiaries, interaction terms of MAA and year dummies, and an interaction term of MAA and a dummy for having experienced mandatory retirement.

The regression sample consists of men aged sixty to sixty-nine. I do not include individuals aged fifty-five to fifty-nine because the information on their public pension status is not derivable from the data. (In any case, most of these people do not yet receive pension benefits.) I also exclude observations for individuals about whom information on any of the variables included in the regression analysis is missing..$^{25}$

The descriptive statistics for the total sample are shown in table 9.6. First, using Sample 1 data, I estimate probit models for the decision to

25. An exception to this rule is treatment of a dummy for having experienced mandatory retirement. In the SECOP-IP questionnaire, anyone who answered no to the question "Were you an employee at age 55?" was not asked "Have you experienced mandatory retirement?" (see note 18). For these men, because the dummy for having experienced mandatory retirement is missing, I assign zero to the mandatory retirement dummy. I also include a dummy variable for nonemployment at age fifty-five for such individuals, to distinguish them from men who have not retired from career jobs. 
Descriptive Statistics of the Regression Sample

\begin{tabular}{|c|c|c|c|c|}
\hline & \multicolumn{2}{|c|}{ Sample 1} & \multicolumn{2}{|c|}{ Sample 2} \\
\hline & Mean & S.D. & Mean & S.E. \\
\hline Worked & 0.622 & 0.485 & 0.588 & 0.492 \\
\hline Employed in the private sector & 0.333 & 0.471 & 0.273 & 0.446 \\
\hline Full-time work (weekly hours $>35$ ) & 0.435 & 0.496 & 0.384 & 0.486 \\
\hline Weekly hours (worked = 1 only) & 38.18 & 14.58 & 37.10 & 15.15 \\
\hline Log hourly wage ( 10,000 yen) & 0.158 & 0.192 & 0.152 & 0.195 \\
\hline Ages $60-64$ & 0.576 & 0.494 & 0.538 & 0.499 \\
\hline Single & 0.038 & 0.190 & 0.038 & 0.191 \\
\hline Couple & 0.346 & 0.476 & 0.344 & 0.475 \\
\hline With dependent children & 0.441 & 0.497 & 0.430 & 0.495 \\
\hline Supported by children & 0.114 & 0.317 & 0.122 & 0.328 \\
\hline Live in Tokyo & 0.092 & 0.289 & 0.089 & 0.285 \\
\hline Executives & 0.079 & 0.269 & 0.062 & 0.242 \\
\hline Self-employed & 0.212 & 0.409 & 0.231 & 0.421 \\
\hline NonEP job $^{a}$ & 0.065 & 0.247 & 0.071 & 0.257 \\
\hline Experienced mandatory retirement & 0.418 & 0.493 & 0.426 & 0.495 \\
\hline Good health & 0.677 & 0.468 & 0.662 & 0.473 \\
\hline EP eligible (inc. potential eligible) & 0.513 & 0.500 & 0.469 & 0.499 \\
\hline EP $\times$ Age $60-64$ & 0.284 & 0.451 & 0.220 & 0.414 \\
\hline EP $\times$ Age $60-64 \times$ Year 1988 & 0.101 & 0.301 & 0.074 & 0.263 \\
\hline EP $\times$ Age $60-64 \times$ Year 1992 & 0.131 & 0.337 & 0.096 & 0.294 \\
\hline MAA & 0.202 & 0.401 & 0.219 & 0.414 \\
\hline MAA $\times$ Year 1988 & 0.064 & 0.245 & 0.070 & 0.255 \\
\hline MAA $\times$ Year 1992 & 0.077 & 0.266 & 0.084 & 0.277 \\
\hline MAA $\times$ experienced mandatory retirement & 0.132 & 0.339 & 0.144 & 0.351 \\
\hline Public pension ( 10,000 yen $)$ & 11.28 & 8.83 & 10.79 & 8.86 \\
\hline Company pension $(10,000$ yen $)$ & 0.33 & 2.00 & 0.31 & 1.89 \\
\hline$N$ & 20,796 & & 19,226 & \\
\hline
\end{tabular}

Source: SECOP-IP data sets for 1983, 1988, and 1992.

Note: The sample consists of males aged 60 to 69 . Hourly wage, the amount of public pension, and the amount of company pension are all deflated by CPI. For those who were not employed at age 55 , value 0 is assigned to the mandatory retirement dummy.

${ }^{\text {a }}$ Self-employed jobs are excluded.

work and for private-sector employment, and linear regressions for weekly hours among workers (see table 9.7). Second, I estimate the same relationship using Sample 2 data (as shown in table 9.8). Here are my main findings.

1. The coefficient on a dummy of EP eligibility indicates that labor supply of EP eligibles and potential EP eligibles as a whole is not very different from that of other groups. However, EP eligibles aged sixty to sixtyfour, who face benefit reductions if they work, are much less likely to work than other EP eligibles; the coefficient from Sample 2 suggests that they are 14 percent less likely to be employed in the private sector. Furthermore, 


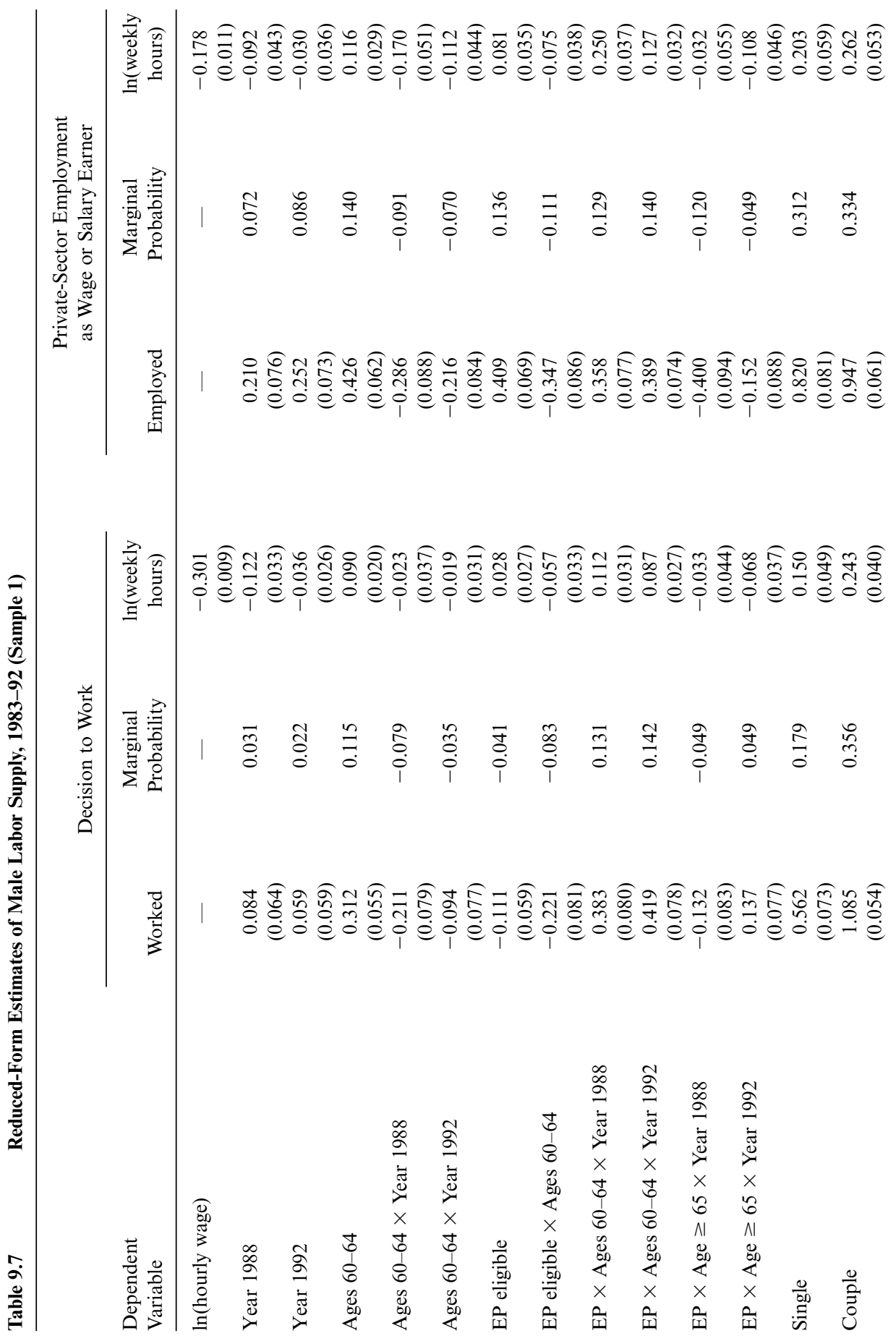




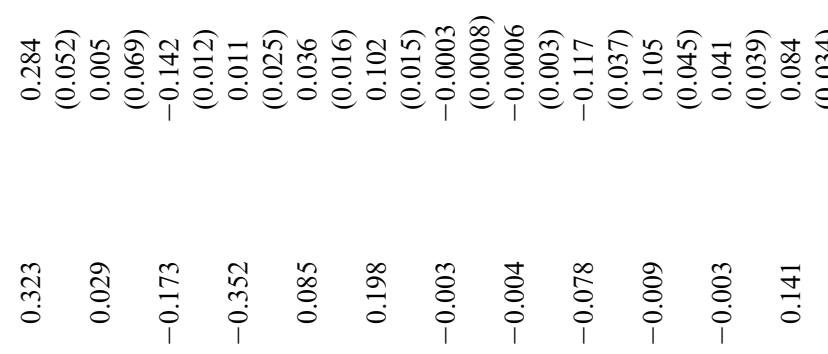

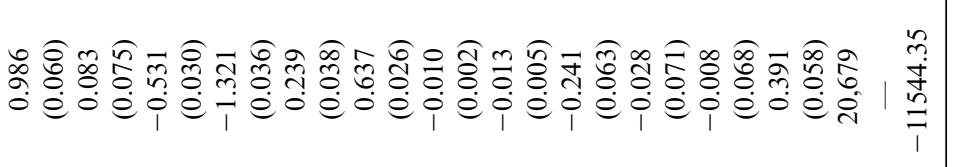

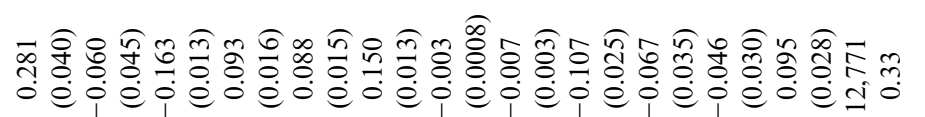

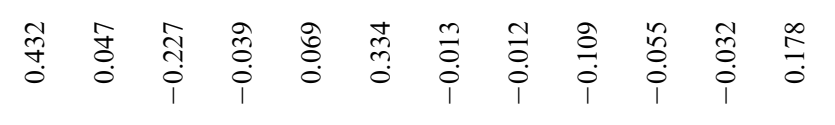

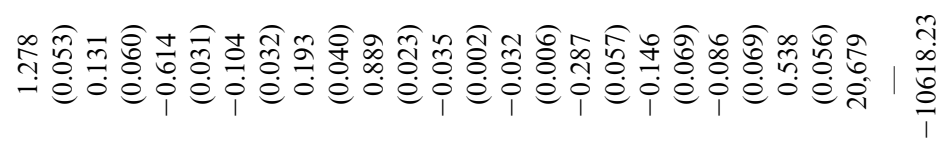



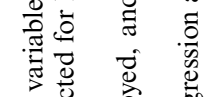

政

就

응

可诺

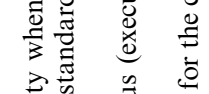

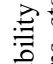

政.

항

尊

言

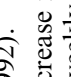

व

巳ँ

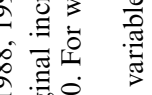

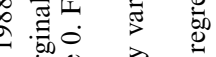



के

ग



.气

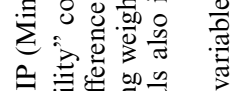

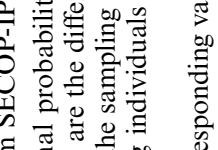

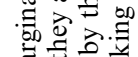

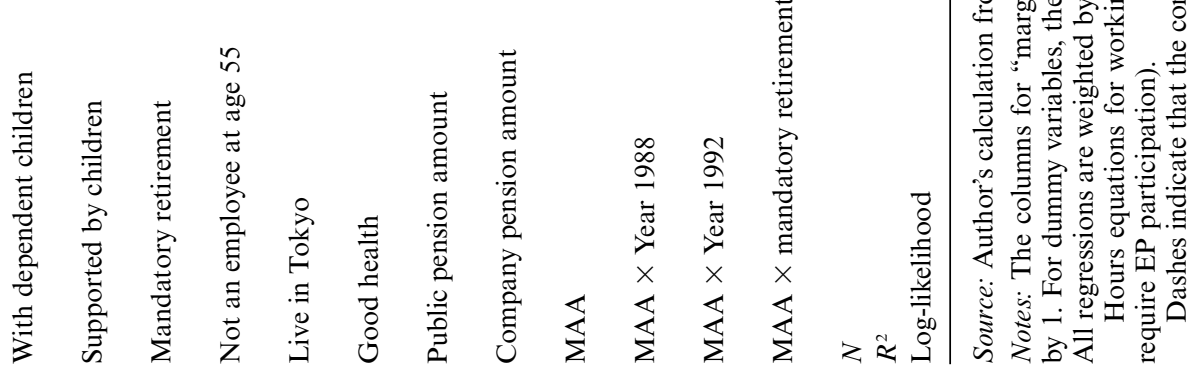




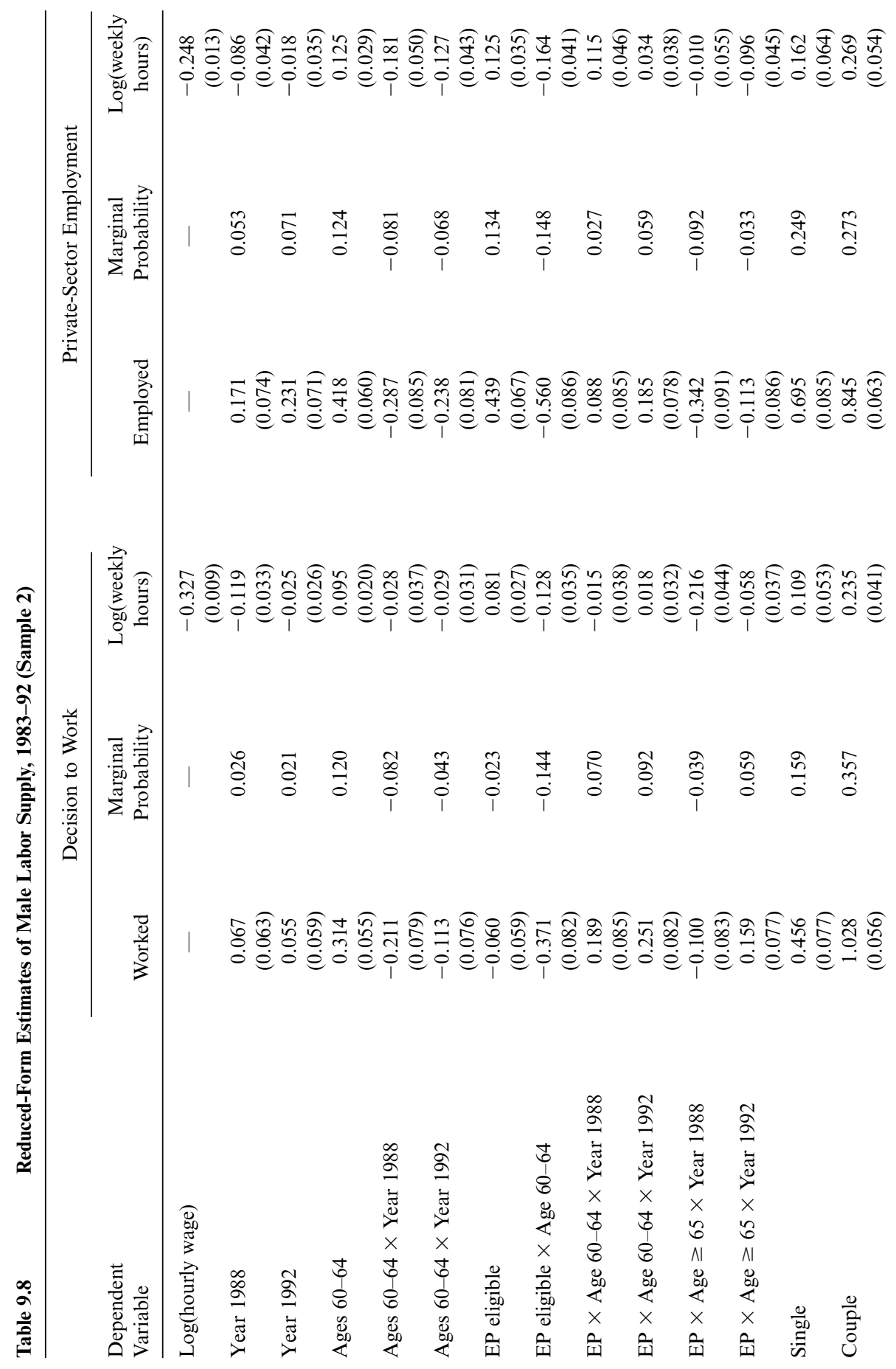




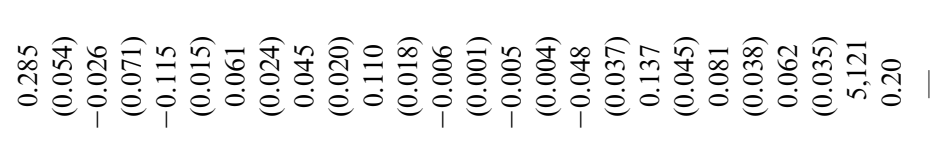

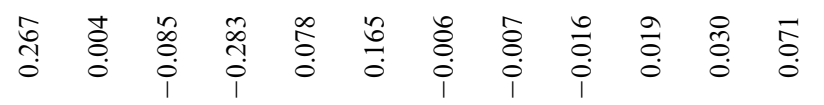

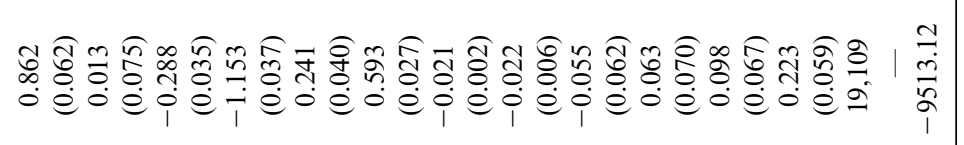

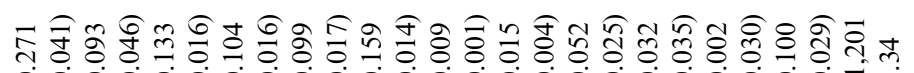
o

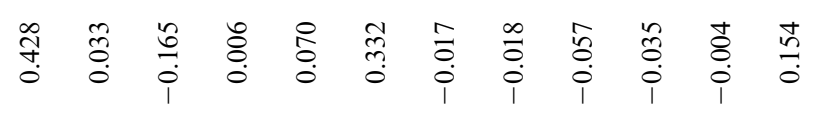

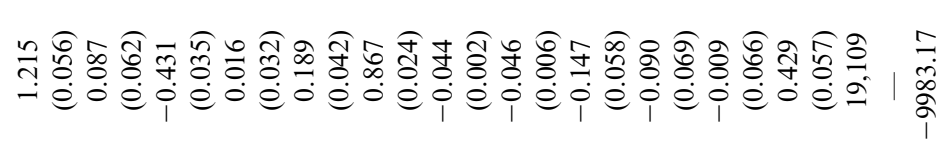

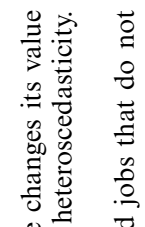

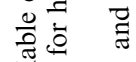

हैं

궁

焉



굴

उ

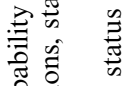

율.

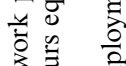

해

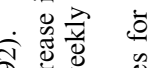

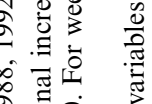

2 后定

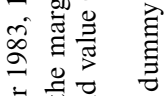

क्षे

$\stackrel{8}{\Xi}$

年

童

要

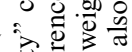

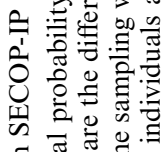

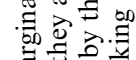

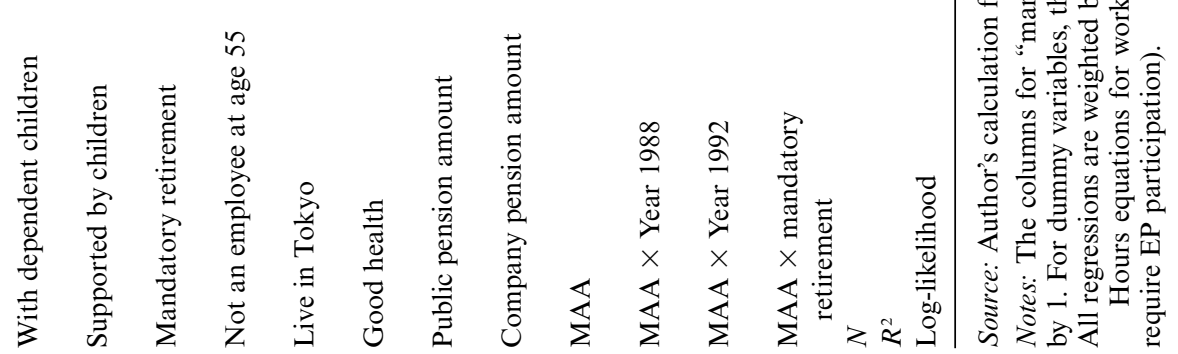


when they do work, their weekly hours are shorter than those of other workers.

2. The coefficients on the interaction terms of EP eligibility, a dummy for age sixty to sixty-four, and year dummies (years 1988 and 1992) indicate that the probability of working and the probability of private-sector employment for EP eligibles aged sixty to sixty-four are higher for 1988 than for 1983 and continue to rise slightly from 1988 to 1992 . The magnitude of these coefficients in Sample 1 (table 9.7) and Sample 2 (table 9.8) differ rather significantly, which makes it difficult to draw a general conclusion. Furthermore, the difference of the coefficients of $(E P) \times($ age $60-64)$ $\times($ Year 1988) and $(E P) \times($ age $60-64) \times($ Year 1992) is statistically insignificant. The coefficients on these variables in weekly hours equations are generally positive but statistically insignificant. Although figures in table 9.5 indicate a large increase in the percentage of working and employed in the private sector among EP eligibles aged sixty to sixty-four between 1988 and 1992, other groups also increased their employment. Thus, the increases for EP eligibles aged sixty to sixty-four were not significantly larger than those of the control group. This finding suggests that the 1989 EPIA reform did not create a significant labor supply response. ${ }^{26}$

3. Older people living in single-person households or being supported by their children tend to work less than other groups do, while those with a spouse or dependent children are more likely to work. Workers who experienced mandatory retirement are also less likely to work. Those who answered "not an employee" at age fifty-five were not so much less likely to work than others, but they are much less likely to be employees: that is, many of them are self-employed (see notes 18 and 25). Good health is also an important factor for determining who works.

I estimate similar regression equations for a sample that excludes those aged sixty years old (results not shown). Because some men of this age have not yet retired from their career jobs, their behavior may be different from that of workers sixty-one to sixty-four years old. Since the mandatory retirement age has increased over time, excluding this group may provide a more accurate description of the labor supply of men in their early sixties. The general pattern of the coefficients for this group is similar to the ones shown in tables 9.7 and 9.8, with the following exceptions. First, the magnitude of the increase in labor supply of the EP group over time is estimated to be somewhat smaller than in Samples 1 and 2, and sometimes not significantly different from zero. Second, unlike the results in tables 9.7 and 9.8, the increase in labor supply of EP eligibles aged sixty-one to sixty-four between 1983 and 1988 is quite small (or insignificant) compared to the increase between 1988 and 1992.

26. In addition, the timing of the labor supply increase is somewhat at odds with that of the policy change, which took effect only in late 1989. 
I also experiment with assigning a different rule for potential EP eligibles by dropping some of the conditions (see note 19). When I use the sample created in this way to do the same analysis as above, the coefficients on most variables have a pattern similar to those shown in tables 9.7 and 9.8. However, the coefficients on the interaction term of EP eligibility, the age sixty to sixty-four dummy, and the year dummies are somewhat sensitive to the assignment of EP eligibility. Therefore, the finding number 2 above is not as robust as the other two results.

In sum, EP benefit reduction does appear to discourage labor supply, although this tendency diminished somewhat between 1983 and 1992. It is not clear that the 1989 reform of EPIA evoked any large labor supply response among the affected group. After controlling for various characteristics, I find that the labor supply of EP eligibles aged sixty to sixty-four had already begun to increase before 1989. Moreover, there is some evidence that private-sector employment for this group continued to increase between 1988 and 1992 .

\subsection{Conclusions and Policy Implications}

My analysis of the microdata for three points in time $(1983,1988$, and 1992) yields three main findings about the effect of the 1989 EPIA reform on labor supply of Japan's elderly men. First, EP benefit reduction for working beneficiaries causes EP eligibles aged sixty to sixty-four to work less than others, suggesting that the benefit reduction scheme in fact depresses the labor supply. Second, based on the regression analysis, it is not clear that the 1989 EPIA reform (which raised the level of income at which benefit reduction took place) increased the labor supply of EP eligibles in that age group. Controlling for year effects and various personal characteristics, I find that labor supply of this group had already increased somewhat between 1983 and 1988, a time frame that does not coincide with the 1989 reform. Furthermore, labor supply of control groups also rose during the same period. Finally, I find that the coefficients of household characteristics, health status, and status for mandatory retirement have the expected sign. The analysis also points to the importance of modeling the pension-application decision and work-mode choice in evaluating any EP benefit reduction scheme.

The EP benefit reduction scheme is a kind of means test for pension benefits: By cutting benefits for those who have positive earnings, the government reduces expenditures while maintaining a stable income for older citizens (although seniors lose leisure time). Such a "growth approach" (i.e., one that increases the resources available for older people) is an attractive choice for an aging economy such as that of Japan, for two reasons. For one thing, older people are healthier than they used to be and so can often continue working into their sixties. For another, such an ap- 
proach eases serious social concerns about the heavy burden placed on younger generations by increasing their contributions to public pension programs.

As a way to diminish these concerns, however, the current administrative rule for EP benefit reductions may have serious loopholes. Workers can avoid benefit reduction by choosing particular modes of work; those who successfully find such forms of employment can receive full benefits without paying EP premiums, even though they have positive labor income. Many such individuals receive benefits as high as those of nonworkers. On the other hand, those who choose to work full time in the private sector and participate in the EP receive reduced benefits and, furthermore, must continue to pay EP premiums. ${ }^{27}$ Thus, horizontal equity among EP eligibles may be violated, depending on individuals' choices of work mode. Such loopholes may also have behavioral consequences, perhaps influencing workers in this age group to find jobs outside the private sector, to work only part time, or-because benefit reduction is severe within the same public pension program - to move across programs to avoid losing benefits. A more comprehensive means test might alleviate some of these inequities.

The analysis I performed was limited to the reduced-form regression. Since the EP benefit reduction scheme creates nonlinearities in the budget constraints in a critical fashion (as shown in panel $\mathrm{C}$ of fig. 9.5) a model to simulate the effects of alternative policies will require us to perform structural estimations. ${ }^{28} \mathrm{I}$ leave that task for future research.

\section{References}

Amemiya, T., and K. Shimono. 1989. An application of nested logit models to the labor supply of the elderly. Economic Studies Quarterly 40:14-22.

Hattori, E. (editor). 1996. Nenkin no kiso-chisiki (Basic knowledge on pension). Tokyo: Jiyū Kokumin Sha.

Ministry of Health and Welfare of Japan. 1995. Nenkin to zaisei (Pension and its financing). Tokyo: Hoken.

- 1996. Annual report on health and welfare 1994-1995. Tokyo: Japan International Corporation of Welfare Services.

Ministry of Health and Welfare of Japan and Social Insurance Agency, eds. 1987.

27. Although future benefits are increased somewhat because of a longer period of contribution, such increases are usually quite modest.

28. The decision structure illustrated in figure 9.4 makes a structural analysis more complicated than the standard labor supply analysis under nonlinear budget constraints. Nevertheless, structural estimation would enable us to simulate the effects of such policy options as reforms in the EP benefit reduction scheme, use of a means tests for benefit determination, and elimination of the income tax deduction for pension benefits. 
Kosei nenkin Hoken Hō kaisetsu (Guide to Employees’ Pension Insurance Act). Tokyo: Shakai Hoken Hōki Kenkyūkai.

Ministry of Labor. 1983, 1988, 1992. Survey on employment conditions of older persons. Tokyo: Ministry of Labor.

1992. General survey of part-time workers 1990. Ministry of Finance: Printing Bureau.

1995. Annual report on employment insurance. Tokyo: Ministry of Labor.

1997. General survey of part-time workers 1995. Ministry of Finance:

Printing Bureau.

. Various years. General survey on wages and working hours system. Tokyo: Ministry of Labor.

Ogawa, H. 1997. "Nenkin ga kōrei-sha no shūgyō koudou ni ataeru eikyū ni tuite" (Labor supply of the elderly and pension benefits). In Nenkin seido kaikaku ga shügyō intai koudou ni oyobosu eikyū ni kansuru kenkyū (Research on pension reform on labor supply and retirement), 17-57. Tokyo: Japan Institute of Labor.

Oguchi, N., Y. Kimura, and T. Hatta. 1996. Redistribution effects of the Japanese public pension system. Review of Social Policy 5:25-52.

Ogura, S. 1994. The cost of aging: Public finance perspectives for Japan. In Economics of aging in the United States and Japan: Economic trends, ed. Y. Noguchi and D. Wise, 139-73. Chicago: University of Chicago Press.

Seike, A. 1993. Kōrei-ka shakai no rōdō shijō (Labor markets in an aged economy). Tokyo: Tōyō Keizai Shinpo Sha.

Seike, A., and H. Shimada. 1994. Social security benefits and the labor supply of the elderly in Japan. In Economics of aging in the United States and Japan: Economic trends, ed. Y. Noguchi and D. Wise, 43-61. Chicago: University of Chicago Press.

Seike, A., and A. Yamada. 1996. "Pension rich no jyoken" (The career job characteristics and pension status of older people). Nihon Keizai Kenkyü (JCER Economic Journal) 33:33-61.

Social Insurance Agency. Various years. Annual report (in Japanese). Tokyo: Social Insurance Agency.

Statistical Bureau, Management and Coordination Agency. Various years. Labor force survey.

Summary of the Social Insurance Policy. 1995. Heisei-7-nendo shakai-hoken jigyō no gaiko. Available at http://www1.mhlw.go.jp./houdou/0902/h0222-1.html.

Tachibanaki, T., and K. Shimono. 1985. Labor supply of the elderly: Their desires and realities about full-time jobs, part-time jobs, self-employed jobs or retirement. Keizai Kenkyū 36:239-50.

1994. Kojin chochiku to life cycle (Personal saving and life cycle). Tokyo: Nihon Keizai Shimbun Sha. 
